\title{
Responses of equatorial anomaly to the October-November 2003 superstorms
}

\author{
B. Zhao ${ }^{1,2,3}$, W. Wan ${ }^{1}$, and L. Liu ${ }^{1}$ \\ ${ }^{1}$ Institute of Geology and Geophysics, Chinese Academy of Sciences, Beijing 100029, China \\ ${ }^{2}$ Wuhan Institute of Physics and Mathematics, CAS, Wuhan 430071, China \\ ${ }^{3}$ Graduate School of Chinese Academy of Sciences, Beijing, China
}

Received: 8 May 2004 - Revised: 2 December 2004 - Accepted: 16 December 2004 - Published: 30 March 2005

\begin{abstract}
The responses of Equatorial Ionization Anomaly (EIA) to the superstorms of October-November 2003 were investigated using the total electron content (TEC) measured with global positioning system (GPS) receivers in China, Southeast Asia, Australian (CSAA), and the American regions. Enhanced EIA was seen to be correlated with the southward turning of the interplanetary magnetic field $B_{z}$. In both the CSAA and American regions, EIA was intensified, corresponding to a large increase in the F-layer peak height $(h m F 2)$ measured by ionosonde and digisonde at middle and equatorial latitudes. However, the enhanced EIA was shown to be more significant during the daytime in the American region, which was associated with a series of large substorms when $B_{z}$ was stable southward. The prompt penetration electric field and the wind disturbances dynamo electric field are suggested to be responsible for this observation according to current theory, although some features cannot be totally decipherable. Both the ionogram and magnetometer data show the existence of a weak shielding effect whose effect still needs further study. A clear asymmetric ionospheric response was shown in our TEC observations, even though it was only one month after autumnal equinox. The southern EIA crest was totally obliterated on 29 and 30 October in the CSAA region and on 31 October in the American region. Ion temperatures from the Defense Meteorological Satellite Program (DMSP) spacecraft revealed that the unequal energy injection at the polar region might be the reason for this effect. It is concluded that different physical processes have varying degrees of importance on the evolution of EIA in the CSAA and American regions.
\end{abstract}

Keywords. Ionosphere (Equatorial ionosphere; Ionospheremagnetosphere interactions; Ionospheric disturbances)

\section{Introduction}

The ionospheric response to a geomagnetic storm, known as the ionospheric storm, has received extensive studies over past decades. Many studies have focused on the ionosphere at middle and high latitudes (e.g. Prölss, 1995; Buonsanto, 1999). However, our understanding of the ionospheric storm at the Equatorial Ionization Anomaly (EIA) area seems unsatisfactory (Abdu et al., 1991). EIA serves as an indicator of the electric coupling status in the solar wind-magnetosphereionosphere system. When this system interaction is enhanced, EIA development can undergo a drastic modification and manifest a complex morphology because of the combined effects of the prompt penetration electric field, the wind disturbance dynamo electric field, storm-induced meridional winds and the composition changes (Prölss, 1995, and references therein). Generally, EIA responses to the above disturbances could, in principle, be separated based on the time response of the observed effect, which is prompt and somewhat delayed with respect to the onset of an interplanetary magnetospheric-high-latitude disturbance event. An attempt to classify the ionospheric effects at a low-latitude station has been made by Adeniyi (1986), according to the occurrences times of the initial and main storm phases.

Recently, significant work of separating local time and storm time variations has been established in equatorial zone electric field data by Fejer and Scherliess (1995, 1997). By binning Jicamarca $\left(11.9^{\circ} \mathrm{S}, 76.8^{\circ} \mathrm{W}\right.$, dip $\left.2^{\circ}\right)$ vertical $\boldsymbol{E} \times \boldsymbol{B}$ plasma drift data according to local time and the time from major perturbations in the geomagnetic auroral electrojet index, Fejer and his colleagues separated the effects of the prompt penetration electric field from those of the disturbance dynamo electric field. However, this classification becomes more difficult when a very large magnetic storm occurs. Considering this, focus was given to identify low-latitude ionospheric responses when a large number of sequential substorm events occurred (Sobral et al., 1997), and also when exceptionally high-intensity and longduration magnetic storms (Sobral et al., 2001) occurred. 


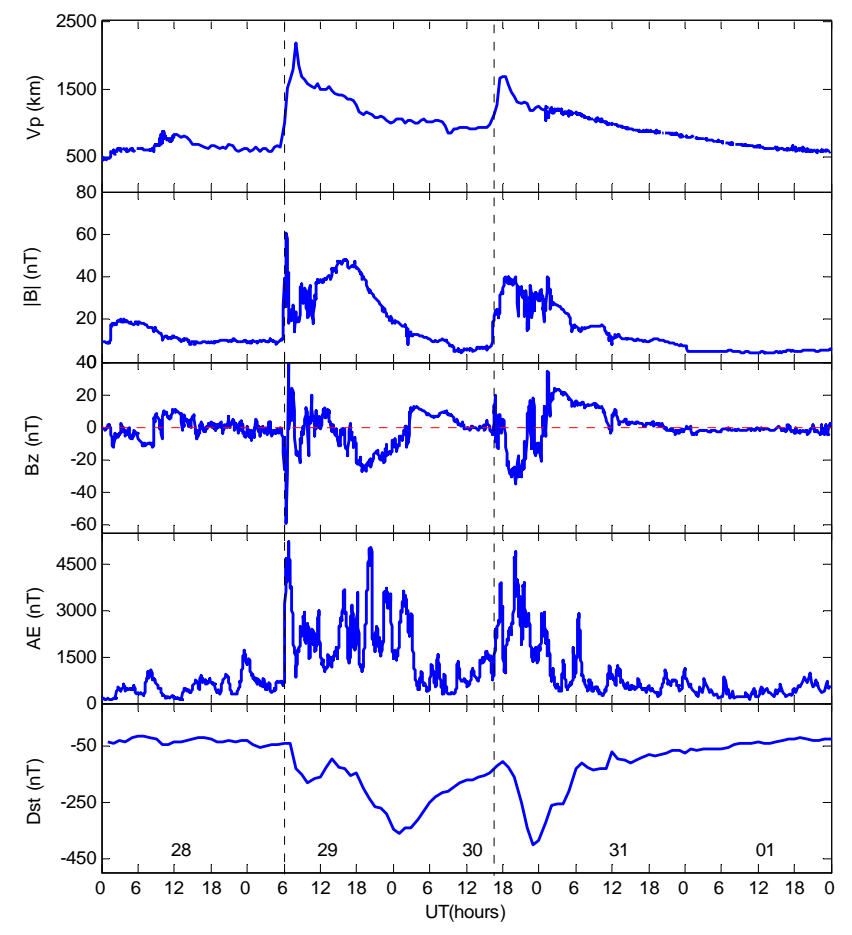

Fig. 1. From the top to bottom are the proton velocity $V_{p}$, magnitude of IMF $B$ and its north-south component $B_{z}$ in the GSE coordinate, $D_{s t}, A E$ indices during the magnetic storm of 28-31 October 2003. Shocks are indicated by vertical dotted line.

These observational results in the South American area partly verified the existing theoretical model (Senior and Blanc, 1984; Tsunomura and Araki, 1984; Spiro et al., 1988), while some others haven't been observed before or were not readily explained by the current model for predicting the penetration/dynamo disturbance electric fields.

Previous studies showed that EIA would undergo drastic modifications under extremely magnetospheric disturbances. For example, the super fountain effects occurred during the great magnetic storm of 15 July 2000, where the width of the EIA trough extended nearly $40^{\circ}$ in the American region (Vlasov et al., 2003). Also, severe magnetic storms can produce a significant depletion of total electron content (TEC) and $f o F 2$ in the EIA area for a long duration. For example, Huang and Cheng (1991), Walker and Wong (1993) and Yeh et al. (1994) detected an unusually large decrease of TEC and $f o F 2$ in the Southeast Asian region during the great magnetic storm of 13 March 1989. The October-November 2003 storms have provided a good opportunity to investigate the EIA response during periods of consecutive extremely high geomagnetic stress. It is likely to expect unusual ionospheric responses in the EIA region for this event. Our goal is to present observational results and try to analyze them with current theories. By using TEC maps derived from the GPS network, we are able to outline the EIA responses to the impacts of consecutive interplanetary events. The ionogram data at two conjugate longitudes (CSAA and American) are used to identify some basic processes related to the solar-magnetosphere-ionosphere coupling. We expect to reveal some fascinating phenomena which have never been reported before.

\section{Solar-terrestrial conditions}

The Sun was extremely active during October 2003. It started a series of X-class flares on 19 October. Following these large flare events, coronal mass ejections (CMEs) took between a few hours to several days to arrive at the Earth, causing the well-known geomagnetic storms. Among these storms two cases on 29 and 30 October were most prominent as they were caused by two consecutive, extremely huge flares. Both flares were produced from the large, complex sunspot group \#10 486 which was active near the solar disk center. The first one, classified as an X-17.2 flare based on the NOAA GOES X-ray measurements, started at 09:51 UT on 28 October and lasted $93 \mathrm{~min}$. The second one was categorized as an $\mathrm{X}-10$ flare, which occurred at 20:37 UT on 29 October and lasted $24 \mathrm{~min}$. The upper and middle panels of Fig. 1 illustrate variations in the proton speed $V_{p}$, the magnitude of interplanetary magnetic field (IMF) $|B|$ and its north-south component $B_{z}$ that were measured from the ACE satellite for the interval 28 October to 1 November. The CME-induced shocks associated with the two flares above were detected by the SWEPAM instrument on the ACE spacecraft at 05:58 UT on 29 October $\left(\mathrm{X}_{\mathrm{gse}}=231.75 R_{E}, \mathrm{Y}=41.24, \mathrm{Z}=-20.74\right)$, and 16:19 UT on 30 October $(X=232.15, Y=41.22, Z=-20.33)$. Following the 29 October shock, $B_{z}$ once reached $-60 \mathrm{nT}$ but generally was only moderately southward and was disrupted by a strong northward turning during this interval. Following the 30 October shock, $B_{z}$ reached the minimum of $-35 \mathrm{nT}$ and persisted for a few hours. Between the two shocks, a relatively negative $B_{z}$ endured that was initiated at around 14:00 UT on 29 October and lasted nearly $12 \mathrm{~h}$. Proton speed $V_{p}$ showed a sharp increase from $\sim 673 \mathrm{~km} / \mathrm{s}$ to $\sim 1487 \mathrm{~km} / \mathrm{s}$ for the first shock event and from $\sim 950 \mathrm{~km} / \mathrm{s}$ to $\sim 1110 \mathrm{~km} / \mathrm{s}$ for the second shock event, giving an $\sim 15 \mathrm{~min}$ and $\sim 21$ min delay for the solar wind to travel to the Earth is magnetospause. The solar wind speed reached an extremely high level $(>1500 \mathrm{~km} / \mathrm{s})$ during two intervals, shortly after the shocks on 29 October and 30 October, with the highest speeds observed $2 \mathrm{~h}$ following each shock. In fact, the measurement of $V_{p}$ became invalid at 07:59 UT on 29 October since the solar wind speed at this time exceeded the SWEPAM measurement limit of $1850 \mathrm{~km} / \mathrm{s}$. Detailed information on the solar wind speed during 28-30 October was given by Skoug et al. (2004).

The bottom panels of Fig. 1 display the evolution of the $A E$ and $D_{s t}$ indices. The $A E$ index is calculated from 65 stations between latitudes $52.9^{\circ}$ and $76.3^{\circ}$ in the corrected geomagnetic coordinates. As shown in the figure, the solar storms had caused great changes in the electromagnetic environment of the Earth about $20 \mathrm{~h}$ after their eruptions. Dayside deviations of the $H$ component of the 
STEP magnetometers along magnetic longitude $\sim 210^{\circ}$ (see website http://stdb2.stelab.nagoya-u.ac.jp/mm210/) recorded a sudden storm commencement (SSC) at about 06:13 UT on 29 October which was characterized by a sudden increase of more than $100 \mathrm{nT}$. After the SSC, the $D_{s t}$ index reached its minimum of $-180 \mathrm{nT},-363 \mathrm{nT}$ and $-401 \mathrm{nT}$ on 29 and 30, respectively. The depression magnitudes of the latter two $D_{s t}$ minima can be comparable to those of the storms produced by the 15 July 2000 and 31 March 2001 CMEs. Extremely large $A E$ increases indicate frequent energy injection into the auroral region during this great space weather event.

\section{Temporal evolution of EIA seen from TEC map}

TEC observations from GPS networks can provide information about perturbation in an EIA ionization distribution (e.g. Buonsanto et al., 1999; Liu et al., 1999; Aponte et al., 2000). Assuming the ionosphere as a single-layer-model, the slant TEC can be converted to vertical TEC as follow:

$\mathrm{VTEC}(\mathrm{UT})=\mathrm{STEC}(\mathrm{UT}) \times \cos \theta+$ Bias.

Universal time was adopted to coordinate the geomagnetic and GPS observations; $\theta$ is the incidence angle at the $400-\mathrm{km}$ altitude of a ray from the GPS satellite to a ground receiver; $\cos \theta$, an obliquity factor, is defined as (Jakowaski, 1996):

$$
\cos \theta=\sqrt{1-\left(\frac{R_{E} \cos \varepsilon}{h_{s p}+R_{E}}\right)^{2}},
$$

where $R_{E}$ is the radius of the Earth, $\varepsilon$ is the elevation angle, and $h_{s p}$ is the height of the sub-ionosphere point, which is usually assumed to be about $400 \mathrm{~km}$.

We were able to obtain the vertical TEC by fitting the Eq. (1). Then through the worldwide GPS network, a nearest interpolation was employed to yield a TEC variation at a single longitude with a spatial resolution of about $2.5^{\circ}$. Thus, we obtained our TEC (Latitude versus UT) map. The sampling interval of all the TEC data we used is $15 \mathrm{~min}$. Two longitudes were selected in our study. One is the geographic $110^{\circ} \mathrm{E}$ sector $(\mathrm{LT}=\mathrm{UT}+8)$, where $\mathrm{TEC}$ data were obtained from a GPS network in China, Southeast Asia and Australia region (CSAA). The other is geographic $70^{\circ} \mathrm{W}$ (LT=UT-5) where the data came from the American network. The distribution of the GPS receivers is given in Fig. 2. The selection of longitude is based on the principle that more GPS receivers are scattered around it at low latitudes. It should be pointed out that the calculation of TEC is perhaps only a very rough approximation since vertical electron density distribution is generally not constant along the ray path. It has been estimated that TEC can be in error by 10-20\% when an elevation-dependent scaling factor is used at low elevation angles $\left(5-10^{\circ}\right)$, and in regions of significant TEC gradients (Klobuchar et al., 1993). However, this approximation is enough for studying large-scale TEC variation, especially under conditions of a large geomagnetic disturbance whose storm effect is very strong.

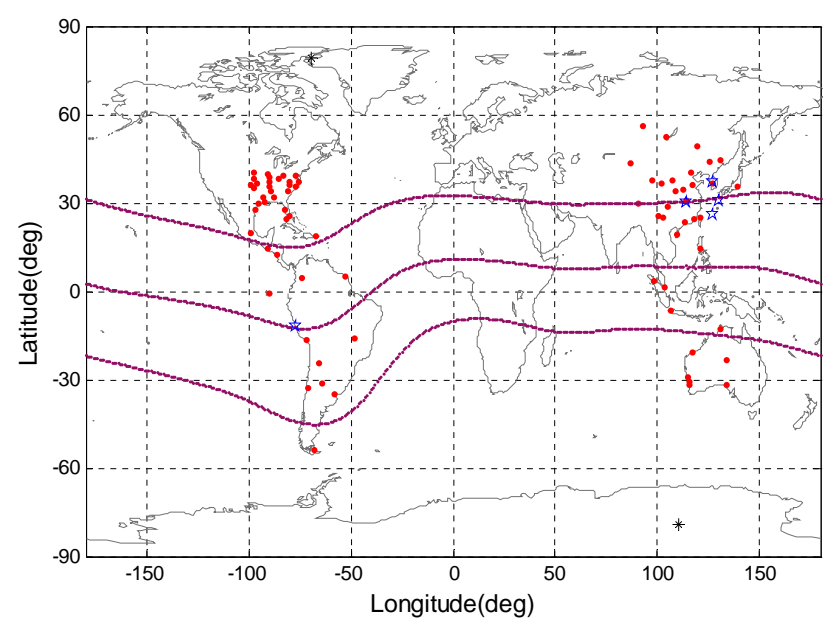

Fig. 2. The dots show the geographic distribution of GPS receivers that were used in our TEC calculation. The dashed lines denote dip latitudes $45^{\circ}, 0^{\circ}$ and $-45^{\circ}$. The five-pointed star marks the location of the ionosonde station. The "*" denotes the location where the magnetic pole locates.

First, we describe the TEC observations according to the schedule of interplanetary events. Figure 3 a reveals the storm changes of TEC at EIA latitudes in the CSAA region and the American region. It can be observed that in the daytime of 29 after 14:00 LT (SSC is denoted by vertical dashed line), the daytime TEC values of two anomaly crests at the longitude $110^{\circ} \mathrm{E}$ increased significantly with their position moving poleward compared with those on 28 . However, double crests evolved into a single crest on 30 , in which the southern peak totally disappeared. The single crest continued to exist on 31 with less severity and recovered to the pre-storm level on the fourth day. The variation of TEC at $70^{\circ} \mathrm{W}$ shows a rather different process from that at $110^{\circ} \mathrm{E}$. The EIA was greatly enhanced on the whole day of 29 , which seemed to be triggered by the second major southward turning of $B_{z}$. This enhanced fountain effect recurred on 30 in answer to the third major southward turning of $B_{z}$. It has been demonstrated that on both 29 and 30 the southern crest was less prominent than the northern one. A similar inhibition of the southern crest was seen on 31 following the corresponding variation in the CSAA region on 30 .

To show more clearly the storm-induced TEC variation, we subtracted the monthly average value to obtain its absolute deviation (DTEC), as shown in Fig. 3b. In the CSAA region a weak equatorial depletion with "two humps" centered on latitudes $\pm 15^{\circ}$, appeared shortly after an extremely southward turning of $B_{z}(-60 \mathrm{nT})$ and an extremely large sudden increase of $A E$. The maxima of the northern and southern anomaly crest DTEC reached $\sim 80$ TEC units and $\sim 60$ TEC units, respectively. More evidently intensified EIAs were observed in the American region during 18:00-24:00 UT on 29 and 30 where the maximum of DTEC was $\sim 120$ and 100 TEC units higher than that on 28. The enhanced EIAs could most probably be caused by the prompt penetration 

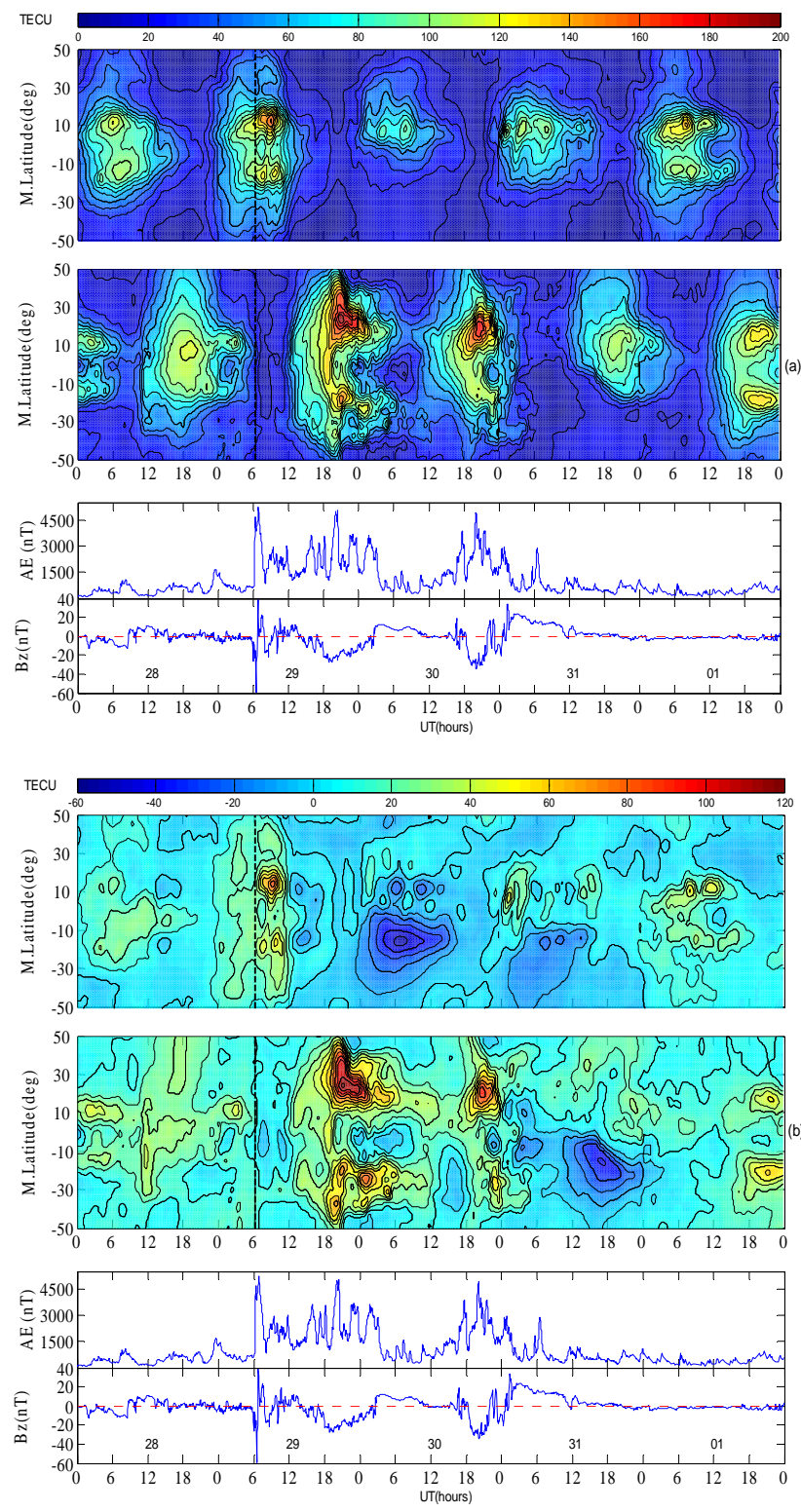

Fig. 3. (a) The TEC variation during the October storm vs universal time and geomagnetic latitude at two longitudes: $110^{\circ} \mathrm{E}$ (top panel) and $70^{\circ} \mathrm{W}$ (middle panel). The bottom panel shows the corresponding AE index and IMF $B_{z}$. the vertical dashed line denotes the SSC. (b) Same as Fig. 3a, but for absolute TEC deviation.

electric fields, which will be discussed in the following section. Upward $\boldsymbol{E} \times \boldsymbol{B}$ drifts, gravity-driven and field-aligned flows combined to move the equatorial plasma outward to higher latitudes. The EIA was also shown to intensify at the nighttime sector between 05:00-10:00 UT on 30 and 31, indicated by negative phases at the equatorial area and positive phases on its flanks. The southern enhanced part on 31 was counteracted by a negative phase that prevailed to the low latitude. The nighttime enhanced EIA should be the result of wind disturbance dynamo electric field effects as predicted by Blanc and Richmond (1980).

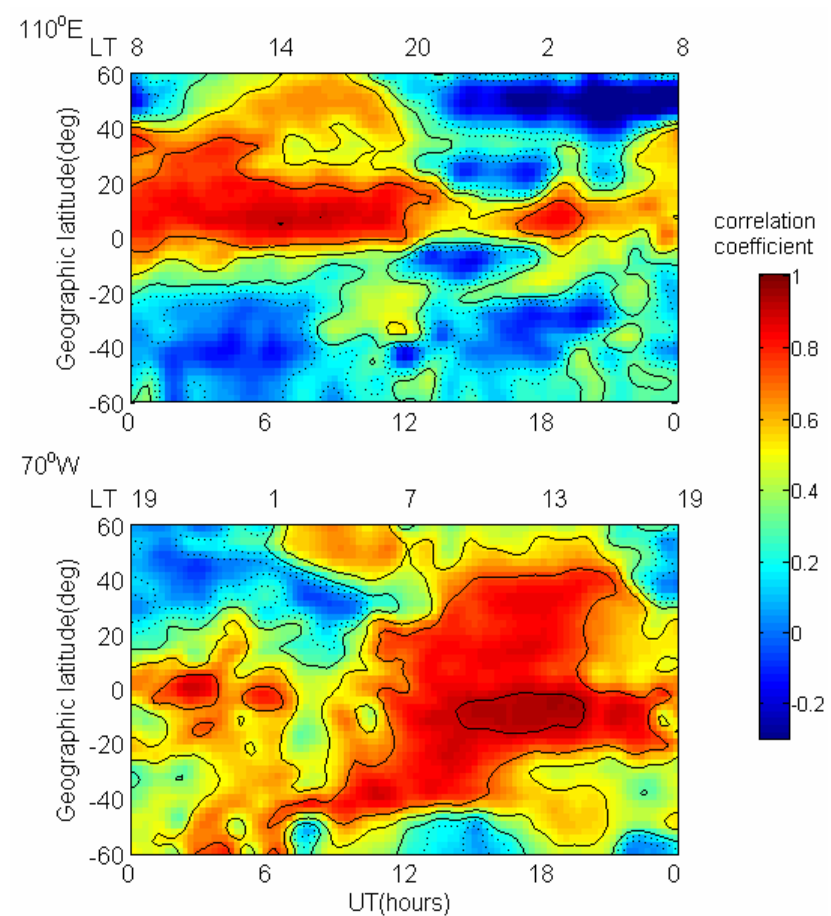

Fig. 4. The dirunal correlation coefficient between solar flux F10.7 and TEC value for the longitude $110^{\circ} \mathrm{E}$ and $70^{\circ} \mathrm{W}$ during October 2003.

It can be observed that the TEC abatements at the equatorial area for all the events are not proportional to the TEC increments at low latitudes which can be seen in Fig. 3b. As a matter of fact, the daytime value of TEC was highly correlated with the variation of F10.7 during October 2003. Figure 4 shows the correlation coefficients of TEC and F10.7 as a function of geographic latitude and local time. For both the longitude $110^{\circ} \mathrm{E}$ and $70^{\circ} \mathrm{W}$, the correlation coefficients are mostly large $(>=0.8)$ at low latitudes and at the equatorial areas during the daytime and sometimes extend to midnight. This is consistent with what has been revealed by Gupta and Singh (2001) that a TEC value at low latitude is rather positively related with the 27-day cycle variation of the solar flux. Even at middle latitudes, the correlation coefficients are still significant. The results show that the ionosphere was strongly controlled by the solar flux during this month. The F10.7 on 29 and 30 is 275 and 268 units, nearly twice that of the monthly average value of 150 units. Then the unbalance between equatorial small depletion of TEC and the large positive low-latitude TEC deviation could be partly due to higher solar flux during the storm. Another possible causes for the anomalous large enhancement of the northern crest TEC on 29 and 30 at the American region might be associated with storm enhanced density phenomenon (Foster et al., 2002). Mannucci et al. (2003) has observed sunward-moving plume-like TEC structures redistributing from low-latitude to northern mid-latitudes in the American longitude sector on 29 and 30 near 22:00 UT. The situation was suggested to be the result of the erosion of the outer plasmasphere by 
the sub-auroral polarization stream electric field (Foster et al., 2002), which needs to be further studied with multiple instruments.

At the same time, the negative phase (depleted TEC) propagated from high latitude to low latitude. As illustrated in Fig. 3b, on the one hand, the molecular composition bulge (air with increased N2/O) induced by heating could rapidly expand to low latitudes at nighttime in the summer hemisphere. This was in response to the summer-to-winter background wind circulation superposed by the storm-induced equatorward wind surges (Fuller-Rowell et al., 1994). On the other hand, the storm was so great that the persistent equatorward surge was able to overcome the daytime poleward wind and pushed the molecular composition bulge to low-mid latitudes on both hemispheres.

We were surprised to see in Fig. 3b that negative phases were much more pronounced in the Southern Hemisphere on 29 and 30 in the CSAA region and on 31 in the American region. This manifests an asymmetric response of the ionosphere to the geomagnetic storm, although the events occurred only one month after autumnal equinox. As suggested by Fuller-Rowell et al. (1996), the hemispheric difference of the ionospheric response is caused primarily by the seasonal difference of the magnetospheric energy deposition into the polar upper atmosphere and of the background wind field. Since most of the polar region is exposed to the sunlight in the summer hemisphere, more magnetospheric energy is deposited into the summer hemisphere owing to higher conductivity (Banks et al., 1981; Foster et al., 1983). The ion temperature measurement of Defense Meteorological Satellite Program (DMSP) spacecraft may help us understand asymmetric heating in the polar regions of two hemispheres. Figure 5 shows the variation of ion temperature at $840 \mathrm{~km}$ as a function of magnetic latitude and UT during 28 October to 1 November in the Northern Hemisphere (top panels) and in the Southern Hemisphere (bottom panels). The local times of the observations are given on the top of the plots. The storm phase is monitored by $D_{s t}$ and $A E$ indices on the right columns. In both of the two hemispheres, significant increases in ion temperature are observed in all local time sectors (18:00 LT, 06:00 LT, 21:00 LT, and 09:00 LT) during the storm main and recovery phases but are more significant at the post-sunrise sector 06:00 LT and 09:00 LT. In the northern polar region, the area and amplitude of the temperature increase is not so significant compared with that in the Southern Hemisphere. It is proposed that this unequal energy injection may be one reason resulting in the asymmetrical distribution of the negative phase during the storm.

\section{Ground observations}

\subsection{Ionogram data}

The ionosonde station at the equatorial area, providing $\mathrm{F}$ layer parameters such as the F2 layer critical frequency

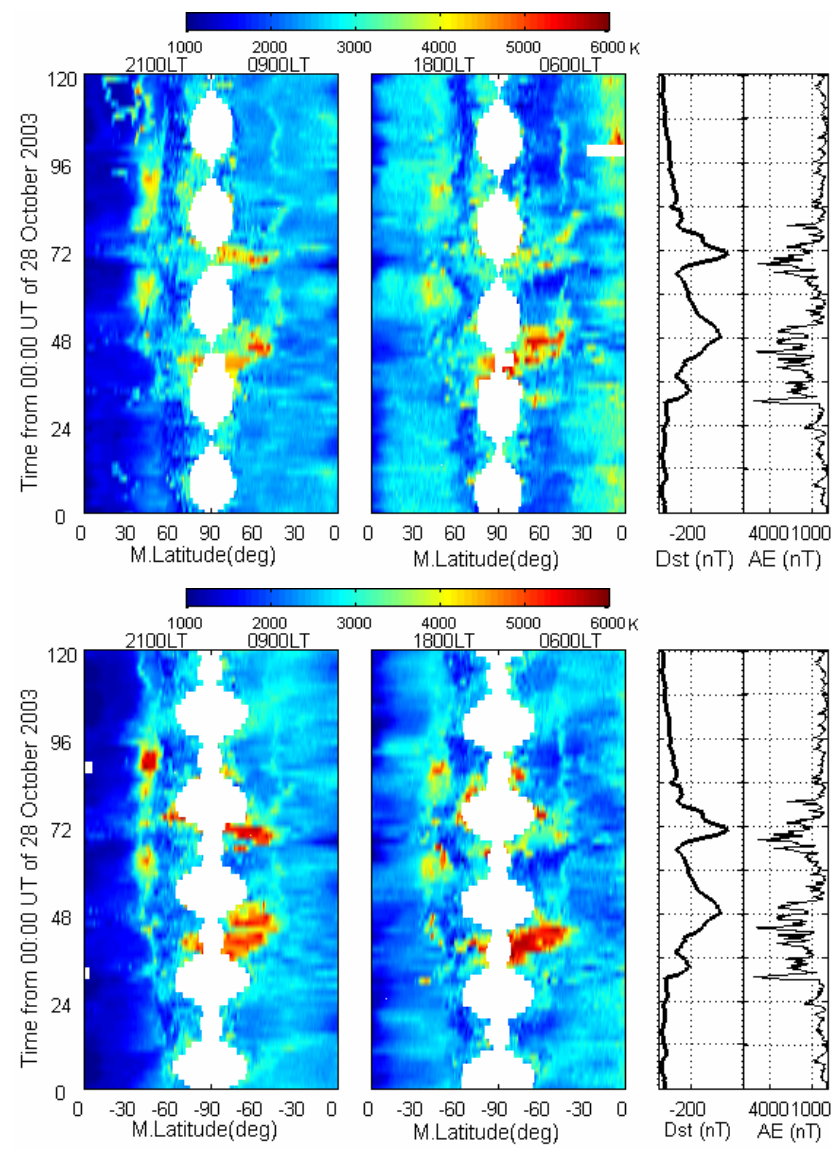

Fig. 5. The variation of ion temperature $T i$ (maglat, UT) in the Northern (upper panel) and Southern Hemisphere (bottom panel) at 21:00 LT, 09:00 LT, 18:00 LT and 06:00 LT measured by DMSP $\mathrm{F} 13$ and $\mathrm{F} 15$ at altitude $840 \mathrm{~km}$. The $D_{\text {st }}$ and $A E$ indices are shown at right columns as an indicator of the storm phase.

foF2, the minimum virtual height $h^{\prime} F$, and the peak height $h m F 2$ of the $\mathrm{F}$ layer, can give direct information about the storm-time EIA behavior associated with electric field disturbances. If there were two equatorial stations that were locate separately on the symmetric longitudes, then it would be much helpful to make a comparative study. However, we had only one station at the equatorial area in the American longitude (Jicamarca dip $0.66^{\circ}$ ). Then we made a compromise to use four low-middle latitude stations in the East Asia area (Osan, Wuhan, Yamagawa and Okinawa) as a comparison for Jicamarca. Previous studies have shown that simultaneous height changes in this area can be a good indicator of the electric field (Reddy and Nishida, 1992, Liu et al., 2004). The information about the stations and the sampling intervals are listed in Table 1.

For all the tabulated values in this study, we have used the ionospheric critical frequency $f o F 2$. The virtual height $h^{\prime} F$, directly scaled from the ionogram, was not appropriate as an indicator of the layer height for the analysis through the day, because $h^{\prime} F$ is strongly affected in the daytime by production and loss processes at the bottom of the layer, irrespective 
Table 1. Information about stations from which ionogram and magnetmeter data were collected in this storm study.

\begin{tabular}{lrrrrr}
\hline $\begin{array}{l}\text { Station } \\
\text { Name }\end{array}$ & $\begin{array}{r}\text { Glat. } \\
(\mathrm{deg})\end{array}$ & $\begin{array}{l}\text { Glon. } \\
(\mathrm{deg})\end{array}$ & $\begin{array}{r}\text { Mlat } \\
(\mathrm{deg})\end{array}$ & $\begin{array}{r}\text { Dip } \\
(\mathrm{deg})\end{array}$ & $\begin{array}{r}\text { Time space } \\
(\mathrm{min})\end{array}$ \\
\hline Ionogram data & & & & & \\
Osan AB & 37.1 & 127.0 & 27.3 & 53.5 & 15 \\
Yamagawa & 31.2 & 130.6 & 20.4 & 44.1 & 60 \\
Wuhan & 30.5 & 114.4 & 19.1 & 45.8 & 15 \\
Okinawa & 26.3 & 127.8 & 15.3 & 36.8 & 60 \\
Jicamarca & -12.0 & 283.2 & 0.64 & -1.7 & 1 \\
Magnetometer data & & & & & \\
Jicamarca (JIC) & -12.0 & 283.2 & 0.64 & -1.7 & 1 \\
Piura (PIU) & -5.2 & 279.3 & 7.1 & 13.6 & 1 \\
\hline
\end{tabular}

of the $\mathrm{F}$ layer dynamics. Instead, the peak height of the $\mathrm{F}$ layer, $h m F 2$, was utilized. The ionogram of digisonde origin was automatically scaled by using the ARTIST inversion algorithm (Gamache et al., 1992) to obtain a true height and subsequently were manually rescaled. The ARTIST program does not provide an error estimate for $h m F 2$. However, limits on the error in $h m F 2$ were given by Dyson et al. (1997), which showed that the error will not exceed $20 \mathrm{~km}$ in the daytime but may become tens of kilometers at night. For ionosonde data, $h m F 2$ was evaluated based on an empirical formula that was developed by Dudeney (1983) as

$h m F 2=\frac{1490}{M(3000) F 2+\Delta M}-176(\mathrm{~km})$

$\Delta M=\frac{0.253 \pm 0.008}{X_{E}-1.215}-(0.012 \pm 0.009)$

$X_{E}=\frac{f o F 2}{f o E}$,

$f o E$ appears in the formula, but its scaling was often affected by the sporadic $\mathrm{E}$ and interferences, and empirically determined values of $f o E$ (Buonsanto and Titheridge, 1987) were adopted instead of an absent value. According to Dudeney (1983), the equations give the best overall performance with an RMS error of about 5\% comparing with the other empirical formulas at magnetic mid-latitudes. The above estimation of $h m F 2$ is less satisfactory during the storm time because of uncertain $f o E$ value; nevertheless, it provides qualitative information of the storm ionosphere behavior when simultaneous height disturbances occur.

Figures $6 \mathrm{a}, \mathrm{b}$ and $\mathrm{c}$ present the ionospheric responses during three periods when $D_{s t}$ experienced main and recovery phases: 03:00-14:00 UT on 29 for the first event, 14:00 UT on 29 to 11:00 UT on 30 for the second event, 12:00 UT on 30 to 11:00 UT on 31 October for the third event. All the parameters of storm-time (circle) are compared with their monthly average values (dot). $A E$ and $B_{z}$ are presented in each of the figures for comparison. It should be noted that the $B_{z}$ was shifted by $15 \mathrm{~min}$ to the right for Figs. $6 \mathrm{a}, \mathrm{b}$ and
21 min for Fig. 6c, which is the time needed for the shock to travel from the ACE satellite's position to the magnetospause.

Generally, the prompt penetration electric field of the magnetospheric origin can be divided into two types: a) a southward turning of IMF $B_{z}$ that marks an enhanced magnetospheric convection, and the onset of an auroral substorm that produces a dawn-dusk electric field (i.e. eastward/westward on the day/night sides) in the equatorial ionosphere (e.g. Fejer et al., 1979; Fejer, 1986; Sastri et al., 1992); b) after a typical duration of one to several hours, the substorm is terminated by a northward turning of $B_{z}$ with an associated reduced convection electric field when the dusk-dawn electric field is established (e.g. Kelley et al., 1979; Gonzales et al., 1979; Spiro et al., 1988). The prompt penetration electric fields of the above two types are about to cause distinct height disturbances in the equatorial area. Besides, Blanc and Richmond (1980) showed that the zonal component of the disturbance dynamo electric fields is westward during the day and eastward at night, resulting in a downward and upward equatorial F-region plasma drift. However, our main difficulty for specifying one by one a cause-effect relationship between IMF/auroral activity and the equatorial F-region response may be the definition of the substorm, since it is not unique. Here we take the approach of Sobral (1997) to define a substorm event as being represented by a rapid increase in the $A E$ index that generally lasts for one to a few hours before it decays rapidly.

As shown in the top panel of Fig. $6 \mathrm{a}, B_{z}$ witnessed a southward turning of about $-20 \mathrm{nT}$ at around 06:13 UT on 29. Then after a few minutes of northward interruption, it reached an extremely large value of about $-50 \mathrm{nT}$. $A E$ increased rapidly following the southward turning of $B_{z}$. In the middle panel at Jicamarca, $h m F 2$ showed a $100-\mathrm{km}$ decrease below the reference value during the interval, suggesting a westward perturbed electric field penetrating to the equatorial ionosphere. The bottom panels shows that very weak increases of $h m F 2$ were perceived at the East Asian stations of Yamagawa, Wuhan and Okinawa simultaneously. 

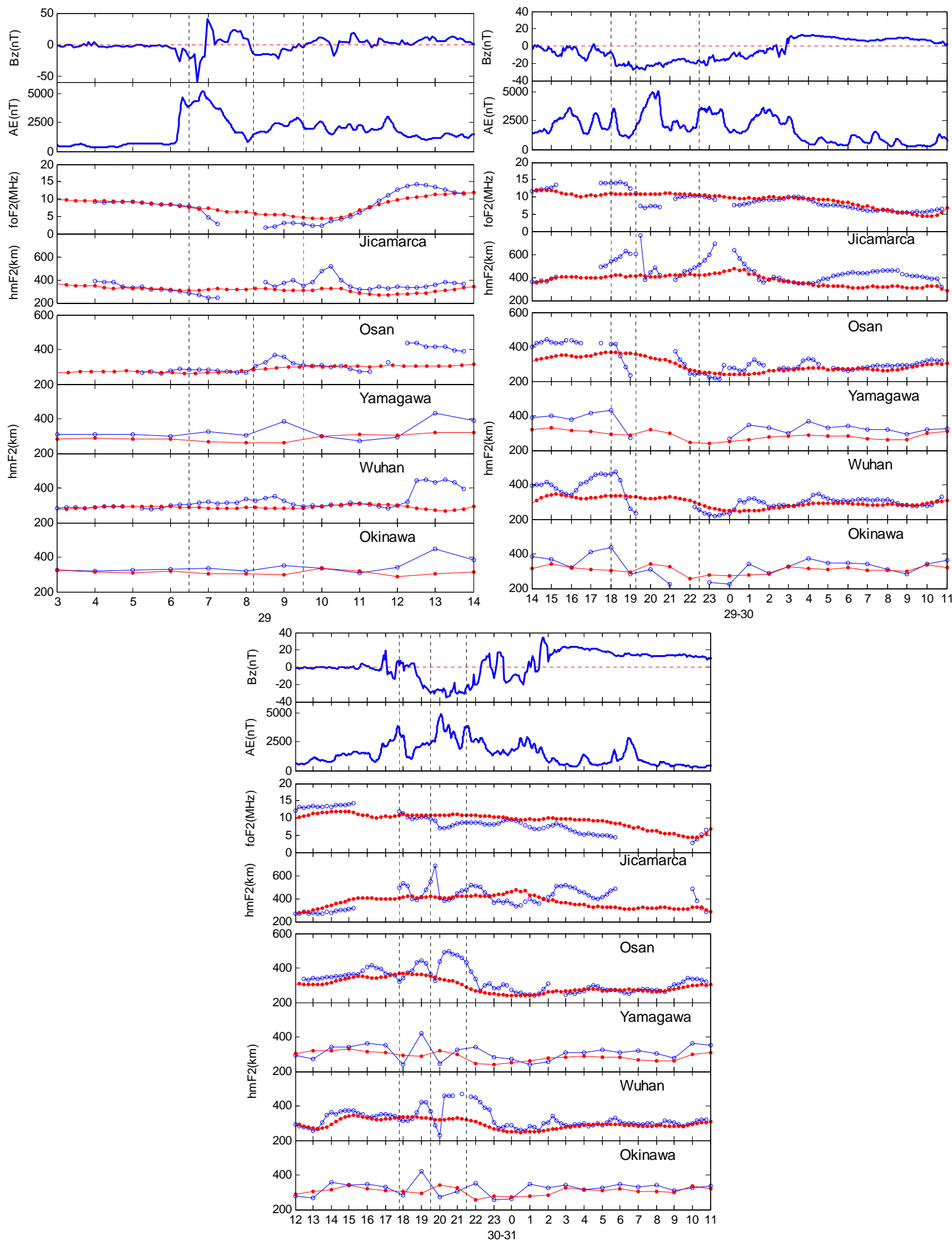

Fig. 6. (a) The top panel shows the corresponding $A E$ index and IMF $B_{z}$ during 03:00-14:00 UT, 29 October 2003. The $B_{z}$ has been shifted to the right by $15 \mathrm{~min}$, which is needed for the shock to travel from the ACE satellites's position to the magnetopause. The middle panel shows the corresponding temporal variations of $h m F 2$ and $f o F 2$ at Jicamarca. The bottom panel displays the $h m F 2$ evolution at the East Asian stations. The red dotted lines denote the monthly average value and the vertical dashed lines mark the distinguished height disturbances. (b) Same as Fig. 6a, but for the period 14:00 UT on 29 October to 11:00 UT on 30. (c) Same as Fig. 6a, but for the period 12:00 UT on 30 October to 11:00 UT on 31. The IMF $B_{z}$ is shifted to the right by $21 \mathrm{~min}$, which is the time needed for the second shock to travel from the ACE satellite's position to the magnetopause. 
The height disturbances may imply the existence of an eastward penetration electric field. Such synchronous height increases in the East Asian area were also observed at 08:00 UT when $B_{z}$ experienced another major southward turning and $A E$ underwent a second large increase. A large eastward electric field probably penetrated to the nightside equator at 09:30 UT when $h m F 2$ at Jicamarca started a nearly 200-km elevation. $B_{z}$ during this period became northward and $A E$ began to decrease. A phenomenon worth noting is that the foF 2 at Jicamarca dropped rapidly following the decline of $h m F 2$ at 07:00 UT. TEC also shows a decrease at this time as presented in Fig. 3b. This post-midnight $f o F 2$ decrease was different from what has been described by Lakshmi et al. (1997), who observed a severe depletion of $f o F 2$ accompanied by an increased $h m F 2 / h^{\prime} F$ in the equatorial area. Thus, they attribute the post-midnight sudden collapse to an enhanced fountain effect. Here the depletion may probably result from a chemical process. During the post-midnight hours, in the absence of production, chemical loss mechanisms dominate in the determination of $N m F 2$ values. As the recombination rate becomes greater at lower altitude, a downward displacement of the $\mathrm{F}$ layer produced by the penetration electric field will therefore lead to a decrease in the ionization density.

Significant enhancements of $h m F 2$ characterized the ionospheric responses at Jicamarca during the period 14:00 UT on the 29 to 11:00 UT on 30, as shown in the middle panel of Fig. $6 \mathrm{~b}$. F layer elevation seemed to be triggered before 18:00 UT when $B_{z}$ turned gradually southward at 15:00 UT. Large increases of $A E$ occurred frequently during 15:00 UT on 29 to 03:00 UT on 30 when $B_{z}$ was southward (sometimes less southward), indicating that continuously enhanced magnetospheric convection occurred during this period. It may be proposed that any magnetospheric disturbances would result in a perturbed electric field penetrated from high latitude. The $h m F 2$ continued to rise until 18:45 UT, followed by a slight decrease. Then it started to give the first striking lift at 19:15 UT associated with a prominent $A E$ of about $5000 \mathrm{nT}$. The second drastic height increase was observed to initiate at about 21:30 UT on 29 which was accompanied by a moderate increase of $A E$, and began to rise rapidly at 22:30 UT when met with another notable $A E$ increment. Actually, the parameters of the F3 layer were adopted by us to replace those of the F2 layer during which the significant height disturbances took place. F3 layer, also called the $\mathrm{G}$ layer, is an additional layer that usually forms during the morning-noon period at altitudes above the F2 peak; its peak density usually can exceed the peak density of the F2 layer and it arises from the vertical $\boldsymbol{E} \times \boldsymbol{B}$ drift at the geomagnetic equator and is modulated by neutral wind (Balan and Bailey, 1995; Balan et al., 1997). Evidence is shown that the peak height of the F2 layer undergoes a rapid decrease if the peak height of the $\mathrm{F}$ layer changes from the F3 layer to the F2 layer (Farley, 1991; Bailey et al., 1993; Preble et al., 1994). That is probably the reason why $h m F 2$ fell quickly from 19:30 UT to 19:45 UT. So this replacement can display well the upward drift but can result in an error in confirming the downward drift of $h m F 2$ associated with electric field disturbances. Figure 7 displays some examples of the track profile of ionograms on 9, 29 and 30 when the F3 layer existed. Normally, the F3 layer at Jicamarca for the quiet day of October (here we selected the date 9) appears for a short period of time just before noon (14:15 UT-14:45 UT) when the $\boldsymbol{E} \times \boldsymbol{B}$ drift starts to decrease (Balan et al., 1998). However, we observed frequently additional abnormal large foF 3 during the storms, which were good indicators with respect to the influence of external disturbed electric fields.

In response to the elevated $\mathrm{F}$ layer at Jicamarca, the $h m F 2$ of the East Asian stations simultaneously present drastic declines at 18:00 UT and 22:00 UT on 29 October, as shown in the bottom panel of Fig. $6 \mathrm{~b}$. The opposite height changes at the sunward and antisunward sectors are consistent with the model prediction (e.g. Spiro et al., 1988; Fejer and Scherliess, 1995) which shows the eastward disturbance electric field between 08:00-20:00 LT and the westward electric field in the 00:00-06:00 LT range. The much longer height increase during 04:00-11:00 UT at Jicamarca on 30 should be attributed to the disturbance dynamo electric field as $B_{z}$ was in stable northward state. This situation is consistent with the theoretical model of Blanc and Richmond (1980) which predicts maximum generation efficiency of the eastward disturbance electric field to occur between 00:00 LT and 04:00 LT.

Figure $6 \mathrm{c}$ shows the ionospheric responses during the period 12:00 UT on 30 to 11:00 UT on 31. The post-sunrise depression of $h m F 2$ during 12:00-15:00 UT at Jicamarca suggested a westward disturbance dynamo electric field which agrees well with the model of Blanc and Richmond (1980) which indicates that a large westward perturbed electric field occurs between 06:00 LT and 10:00 LT. Height increments that occurred at 17:30 UT, 19:00 UT and 21:30 UT on 30, respectively, are shown to correlate well with the increase of the $A E$ index when $B_{z}$ turned southward or was in a southward state. In the Asian region, though the $h m F 2$ displayed a marked enhancement above the reference value since 16:00 UT, due to the storm-intensified midnight equatorward wind circulation, it made two distinct decreases that correspond well with the height disturbances at Jicamarca. The situation shows that the magnetospheric convection electric field has frequently penetrated to the dayside and nightside ionosphere of the Earth when substorms events were triggered.

The post-sunset elevated $h m F 2$ that occurred at 02:00 UT on 31 should be induced by a reduced $A E$ index when $B_{z}$ turned northward. The vacant data during the interval 06:0011:00 UT on 31 October was due to a severe equatorial spread-F (ESF). Somayajulu et al. (1991) has found that the growth of the Rayleigh-Taylor instability became more inducible when the F-region was lifted by the $\boldsymbol{E} \times \boldsymbol{B}$ drift to a higher altitude. So we proposed that the ESF may be caused by an eastward disturbance dynamo electric field that raised the F-layer to high altitudes similar to that which the ionospheric did during 04:00-11:00 UT on 30. The elevated $h^{\prime} F$ (not shown here because of disjointed data) during this vacant period for some time supported this assumption. We 

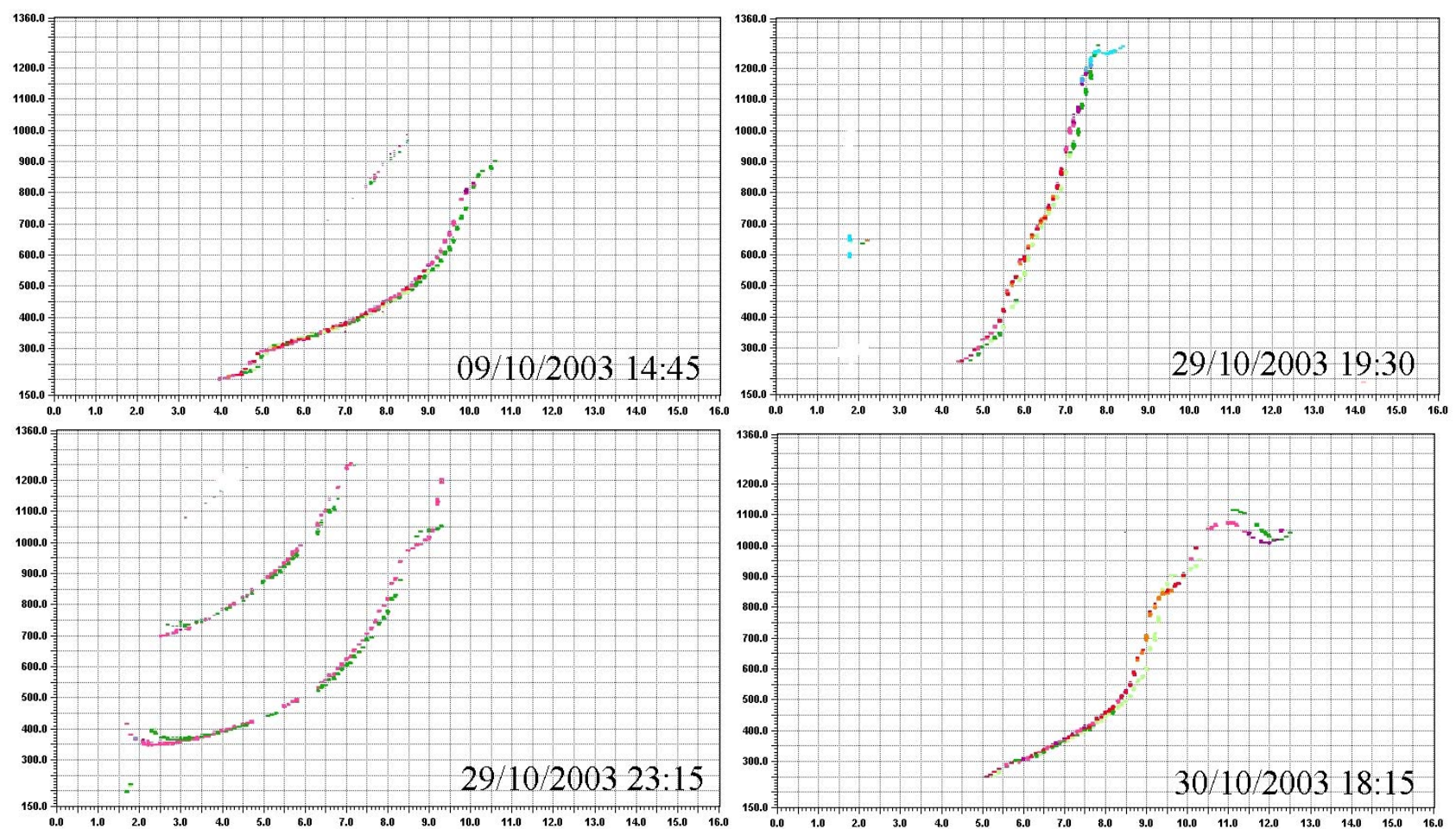

Fig. 7. Examples of ionograms when the F3 layer appeared at Jicamarca on geomagnetic quiet day 9 and disturbed days 29 and 30 October 2003.

may also find that the normal pre-reversal enhancements of $h m F 2$ at 00:00 UT on 31 was inhibited by a steady downward drift, which would suggest a westward perturbed electric field. However, our magnetometer observation shows an enhanced eastward electric field at this time. The inconsistency is unclear and worth further consideration.

It should be noted that the positive deviation of $f o F 2$ at Jicamarca during the daytime 12:00-18:00 UT on the 29 and 30 should be attributed to higher F10.7, comparing with the monthly median value. The $f o F 2$ varied in anti-phase and lagged about an hour, the time that was needed to move the plasma out of the equatorial area, with respect to the variation of the $h m F 2$ during the disturbed period.

\subsection{Magnetometer data}

During the daytime, since the Cowling effect associated with the equatorial electrojet (EEJ) has an amplify function on the equatorial east-west electric field, the difference component of the Horizontal $(H)$ component between a magnetometer placed directly on the magnetic equator and one displaced 6-9 ${ }^{\circ}$ away can be used to derive the vertical $\boldsymbol{E} \times \boldsymbol{B}$ drift in the equatorial F-region (Anderson et al., 2002). This $H$ can eliminate well the effect of the $D_{s t}$ ring current component in $H$ as well as the global Sq Dynamo component of $H$ and only relate to the EEJ contribution because of the magnetometer's special location. Here we used the $H$ component of the ground magnetometers at Piura (PIU) and Jicamarca
(JIC), whose geomagnetic latitudes are $0.8^{\circ} \mathrm{S}$ and $6.8^{\circ} \mathrm{N}$, to present disturbed electric field information during the daytime. Figure 8 illustrates the $H$ component for PIU and JIC and $H$ for JIC-PIU during the period 14:00 UT on 29 to 11:00 UT on 30, panel (a), and 12:00 UT on 30 to 11:00 UT on 31 for panel (b). The dashed line of $H$ represents the value of magnetic quiet day 1 November 2003. The amplitude of the $H$ component at Jicamarca is much larger than that at Piura. Since the Jicamarca magnetometer is closer to the magnetic dip equator, the larger magnetic deviations closer to the equator are clearly related to the EEJ which is enhanced by the eastward electric field through the Cowling effect.

It is shown in panel (a) that the normal EEJ, indicated by the red line, enhanced from 14:00-22:00 UT and kept steady positive/eastward. While during the storm interval 14:00 18:00 UT on 29, the polarity of the EEJ changed swiftly. Each variation did not exceed an hour and varied in-phase with the $A E$ index, which may suggest high-latitude electric fields penetrating to the equatorial ionosphere. The EEJ was greatly enhanced from 18:30 UT to 03:00 UT during the time when $B_{z}$ was in a stable southward state. The same situation occurred during the period from 19:00 UT to 04:00 UT on 30-31, as shown in panel (b). There is a one-to-one correspondence between the F-layer height disturbances at $\mathrm{Ji}_{-}$ camarca and $H$ as indicate by vertical dot line. However, $H$ shows a continuous increase while the height disturbance does not. This is probably because the ionosphere is not 

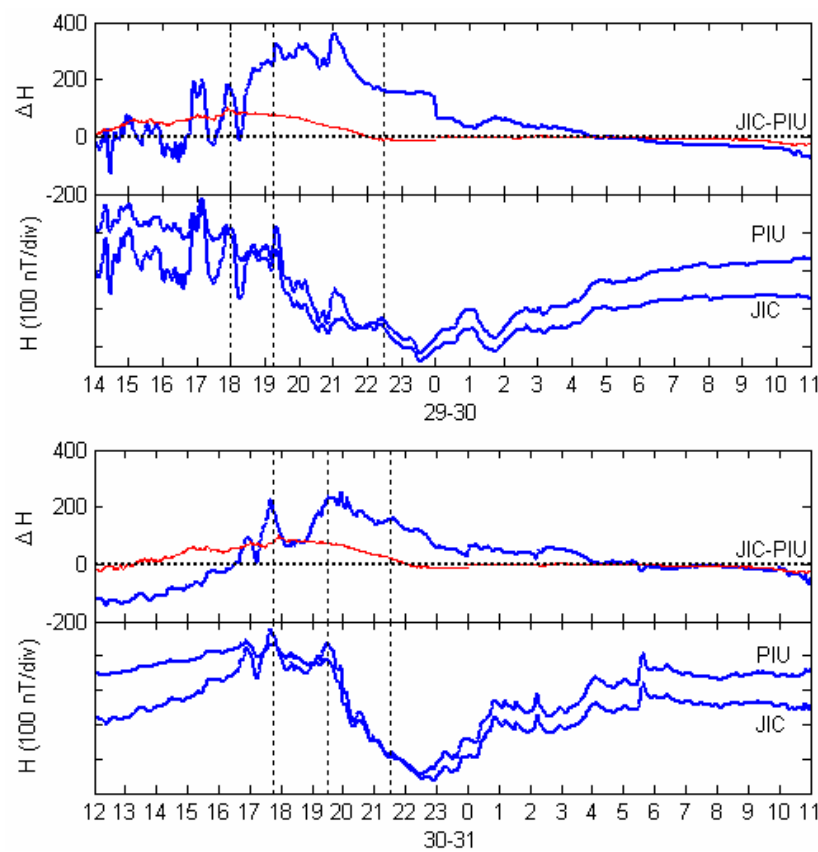

Fig. 8. $H$ component at Jicamarca and Piura and their difference value $\Delta H$ for the period 14:00 UT on 29 to 11:00 UT on 30 (top), 12:00 UT on 30 to 11:00 UT on 31 (bottom). The reference day curve is taken from 1 November. The vertical dashed lines correspond to those in Figs. $6 \mathrm{~b}$ and $\mathrm{c}$.

solely controlled by the electric field. Each time when the plasma was pumped up to the higher altitudes, a certain time was needed for the $\mathrm{F}$ layer bottom plasma to recover to a new balance. The $h m F 2$ fell several hundred kilometers after a drastic elevation due to low plasma density at its origin position. The constant intensified EEJ in the post-noon time sector was prominent for this superstorm event which is different from the past observation that revealed a reduced daytime EEJ (Sastri et al., 1988; Mazaudier and Venkateswaran, 1990). We have found reduced EEJ during 12:00-17:00 UT in panel (b) that should be attributed to a westward disturbance dynamo electric field. The magnetometer data was in agreement with a decreased $h m F 2$, as displayed in Fig. 6c.

\section{Discussion}

The EIA responses to the October-November superstorms can be separated clearly according to three disturbance durations.

Short-term response $(\sim 1-2 \mathrm{~h})$ : Sharp and short-lived plasma drifts in the equatorial area produced by the prompt penetration electric field generally occur during periods of large and rapid changes in the magnetospheric convection, when the inner edge of the plasma sheet, and the region-2 field-aligned currents are configured to counteract a weaker (undershielding) or stronger (overshielding) crosstail (dawn-dusk) electric field (e.g. Vasyliunas, 1972; Wolf et al., 1982; Senior and Blanc, 1984; Spiro et al., 1988). It is shown for this event that shielding/overshelding effects were shown to occur frequently when the magnetosphere was extremely disturbed. Some height disturbances were obvious IMF-driven processes which were associated with the $B_{z}$ polarity reversal. However, large height increases were more often observed for this event when the $B_{z}$ was large and southward but not varying drastically and started nearly simultaneously with the onset of the auroral activity, characterized by a large $A E$ increase. It showed that the shielding effect became rather invalid during the substorm growth and expansive phase. The phenomenon can be well understood using the renovated boundary layer dynamics model of substorms (Rostoker, 1996). As depicted in his Fig. 11b, the space charge due to the term derived by cross-tail current dot earthward convective flow velocities $\boldsymbol{J} \cdot \boldsymbol{v}$ is equivalent to a dusk-to-dawn polarization electric field which effectively shields the inner magnetosphere from the convection electric field across the magnetotail. The growth of a particularly intense cross-tail current near the inner edge of the plasma sheet is terminated by an abrupt collapse marking the onset of the expansive phase of the substorm. The sudden disappearance of this intense cross-tail current can result in the breakdown of the shielding effect associated with region 2 fieldaligned currents. Furthermore, the Spiro's calculation (1988) revealed that the degree of shielding of the mid- and lowlatitude ionosphere depends fairly sensitively on the temperature and density of the plasma sheet particle distribution; for constant plasma pressure, a cool plasma sheet shields the inner magnetosphere much more effectively than a hot plasma sheet; a hot plasma sheet results in poor shielding, even after a relatively long time period of steady convection. We are not about to discuss the relationship between plasma sheet temperature and shielding efficiency for this event, but generally the plasma sheet will be heated during the substorm expansive phase (Baumjohann et al., 1996). A substorm onset that triggers the prompt penetration electric field penetrated to the equatorial area when $B_{z}$ is stable southward was also detected by Fejer et al. (1979). Our observation shows that during extremely magnetic disturbances the process becomes more inducible. The interpretation may explain the continuously enhanced EIA and EEJ at the American longitude during the daytime of 29 that is accompanied by a series of substorms.

Mid-term response (5-6h): The wind disturbance dynamo electric field usually serves as a delayed effect on the equatorial ionosphere. Jicamarca incoherent scatter radar measurement on the F-region vertical plasma drift showed that at Jicamarca the disturbance dynamo related electric field manifests with delays of 16-24 h, with reference to the causative geomagnetic disturbances, and with a marked preference for the postmidnight-prenoon local time sector (Fejer et al., 1983). More recently, statistics analysis made by Scherliess and Fejer (1997), based on thirty years of Jicamarca F region drift data, has found that the delay time associated with the disturbance dynamo electric field effect can separately into two component of $1-12 \mathrm{~h}$ and $22-28 \mathrm{~h}$. The short-term disturbance dynamo drives upward equatorial drifts at night, 
with the largest amplitudes near sunrise and small downward drifts during the day. The longer term drives upward drifts at night, with largest values near midnight and downward drifts in the sunrise-noon sector. Then Fejer and Scherliess (1997) developed an empirical model to determine the linear relationship between the disturbance electric fields and $A E$ values. We employed the model to derive the effects of the prompt penetration electric field and the disturbance electric field for this case. Figure 9 illustrates the storm-time vertical drift in the equatorial zone at $70^{\circ} \mathrm{W}$. The broken, thin solid and thick solid lines represent the drift being produced by the disturbance dynamo electric field, the prompt penetration electric field, and both, respectively. Comparing with the height involution at Jicamarca, the model shows its good prediction ability for the disturbance dynamo electric field during the period 05:00-10:00 UT sector and also the inhibition of pre-reversal enhancement at 00:00 UT. The model predicts the initial downward drift followed by an upward drift shortly after SSC. However, the model underestimates large height increments that are associated with large $A E$ increases. The reason may be that there occurred weak shielding events or the underestimation results from other sources of the prompt penetration electric field. Moreover, a linear dependence of the disturbance electric fields and the $A E$ indices might not be correct for very large $A E$ values. Even with so many uncertainties, the model has proved its prediction ability when met with complicated and drastic magnetospheric disturbances.

Asymmetric Long duration response (2-3 days): Besides the electrodynamic effects, another way to modify the EIA is through wind-induced drifts. Equatorward-directed winds will oppose the poleward transport of ionization along the magnetic field lines. This will hinder the formation of the EIA and generate negative storm effects in the anomaly crest regions and positive storm effects near the equator (Rüster and King, 1976). However, the negative phase for this case extended all the way to the equatorial latitudes, which may suggest a change in the neutral gas composition. Prolonged negative phase at low-latitudes is often associated with very large storms (e.g. Huang and Cheng, 1991). The polar disturbance zone, marked by an increase in the molecular species and a decrease in the atomic oxygen density, can expand to the EIA regions during an intense storm (e.g. Prölss, 1995; Prölss, 1998; Mansilla, 2003). The negative phase presents evident asymmetry that is more significant in the southern crest region. Fuller-Rowell et al. $(1994,1996)$ revealed that there is a rapid equatorward expansion of summer negative storm phase at nighttime owing to the background summerto-winter wind circulation and reduced ion drag. However, the asymmetric distribution of the long-lasting negative phase in the EIA region should not be mainly caused by the summer-to-winter background wind circulation, since the event occurred only one month after equinox. According to DMSP data, we proposed that the unequal energy injection at the polar region should be the main reason for causing asymmetrical distribution of the negative phase. Another mechanism that may account for the long-lasting negative

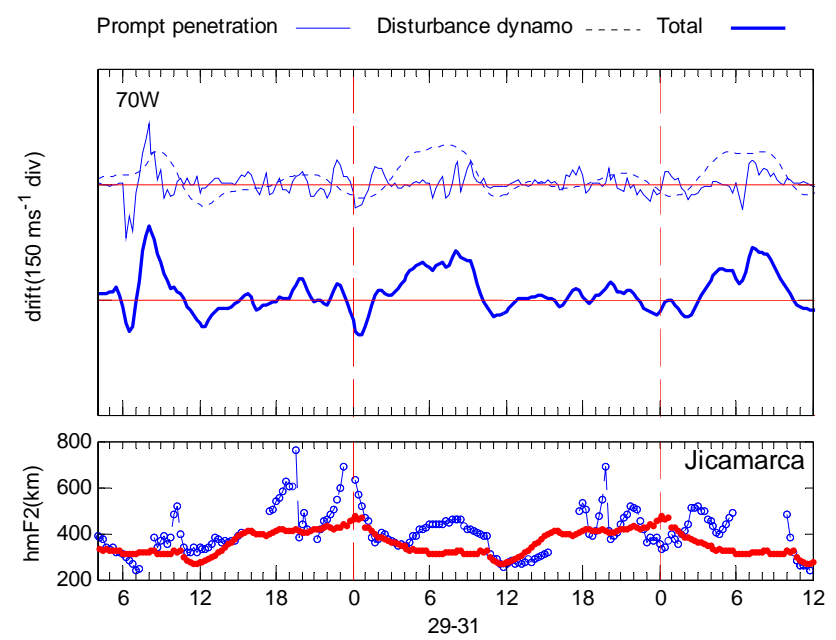

Fig. 9. Top panel displays storm-time upward drifts derived from Fejer and Scherliess's (1997) mode for the longitude $70^{\circ} \mathrm{W}$. The broken, thin solid and thick solid lines each represents the disturbance dynamo electric field drift, prompt penetration electric field drift and the composite drift of these two. Bottom panel shows the storm-time vs. quiet-time $h m F 2$ variations at Jicamarca.

phase that was observed in the CSAA region on 30 and 31 is the role of its geographic location. As pointed out by Rishbeth (1998), the composition disturbance zone may penetrate a few degrees greater equatorward of the auroral oval in the "near-pole" sectors than in the "far from pole" sectors. So the Australian sector (near the south the magnetic pole) is more likely to be under control of the negative phase than the East Asian sector (far from the north magnetic pole). Other possible cause such as an increase in the neutral temperature need, to be verified with further investigation. For the American region, the negative phase was confined at middle latitudes on 29 and 30 October due to a series of enhanced fountain effects. It is evident that the leading force that affected the EIA behavior is the $\boldsymbol{E} \times \boldsymbol{B}$ force. The nighttime enhancement of the EIA produced by the disturbance dynamo electric field during the interval 05:00-10:00 UT on 30 prevented the negative phase from invading the equator at nighttime. However, the crest was inhibited between 05:00-10:00 UT on 31 when a similar large height elevation was seen at Jicamarca. This is understandable if we assume that another composition bulge produced by the large energy injection at the polar region corresponding to the third major $B_{z}$ southward turning has propagated to low latitude.

\section{Summary}

The extremely large magnetic storms afford an opportunity to study in detail the EIA response features. Here we summarize our main observations and conclusions.

Two X-class flares that occurred on 28 and 29 October 2003 induced profound changes in the Earth's ionosphere during the period 29-31. In both the CSAA and American 
regions, a large sudden EIA enhancement was visualized to be triggered when $B_{z}$ suddenly turned southward. For the American region intensified EIA continued existing due to the frequent occurrences of prompt penetration electric fields through our ionosonde data analysis, though some of them cannot be totally explained with the $A E$ and $B_{z}$ variation. Nighttime enhanced EIA should be produced by the disturbance dynamo electric field due to the storm-time circulation, which agrees well with Fejer and Scherliess's (1997) model prediction.

The development of ionospheric responses reflects a characteristic of thermospheric storms. In both the CSAA and American regions the ionospheric storm showed asymmetry. For the former region, the southern EIA crest was totally wiped out on 30 and 31. For the latter region, EIA is more intensified at the northern crest than at the southern one during the daytime of 29 and 30. The southern EIA crest also disappeared on 31. Ions temperature from the Defense Meteorological Satellite Program spacecraft revealed that the unequal energy injection at the polar region may be one of the reasons for this effect.

The observation shows that the impact of the prompt penetration electric field on the EIA was quick but short lived. However, if the magnetic environment permits, it may bring continuous influence that can compete with the other mechanisms such as a chemical process. It is concluded that different physical processes seemed to have varying degrees of importance in the CSAA and American regions, depending on the combined effect of the local time variation of the electric and thermospheric response of the ionosphere.

The role of EIA is very special, as it is part of the solar wind-magnetosphere-ionosphere system, as well as part of thermosphere-ionosphere system. It is reasonable to predict that a greater magnetic storm will result in a stronger ionospheric storm as more energy is injected into the polar region. With the current understanding of the ionospheric storm, we are able to expect some of the ionospheric features at the EIA region, such as anomalously intensified EIA and a long duration negative phase which prevailed at the equatorial area. However, quantitative study needs to be undertaken on exactly how much do these processes contribute to the storm EIA variation.

Acknowledgements. This work is supported by National Science Foundation of China (40134020), the KIP Pilot Project (kzcx3sw-144) of CAS, and National Important Basic Research Project (G2000078407). The authors acknowledge IGS for providing the GPS data in the web site. Special thanks should be given to B. Reinisch for offering the DIDB database and also to K. Igarashi for ionospheric sounding data in Japan. The equatorial $D_{s t}$ data were obtained from World Data Center $\mathrm{C} 2$ for Geomagnetism in Kyoto. $A E$ index is calculated by G. Chen. The authors thank R. M. Skoug for providing ACE satellite data. The authors also express their thanks to the Center for Space Sciences at University of Texas at Dallas and the US Air Force for providing the DMSP thermal plasma data. The authors would like to express especial thanks to L. Scherliess of Utah State University for providing their codes. The Jicamarca Radio Observatory is operated by the Instituto Ge- ofisico del Peru, with support from NSF Cooperative Agreement ATM-9911209 through Cornell University; we thank O. Veliz for providing processed magnetograms from Piura and Jicamarca.

Topical Editor M. Lester thanks two referees for their help in evaluating this paper.

\section{References}

Abdu, M. A., Sobral, J. H. A., Paula, E. R., and Batista, I. S.: Magnetospheric disturbance effects on the Equatorial Ionization Anomaly (EIA): An overview, J. Atmos. Terr. Phys., 53, 757771, 1991.

Adeniyi, J. O.: Magnetic storm effects on the morphology of the equatorial F2-layer, J. Atmos. Terr. Phys., 48, 695-702, 1986.

Anderson, D., Anghel, A., Yumoto, K., Ishitsuka, M., and Kudeki, E.: Estimating daytime vertical $\boldsymbol{E} \times \boldsymbol{B}$ drift velocities in the equatorial F-region using ground-based magnetometer observations, Geophys. Res. Lett., 29(12), 1596, doi:10.1029/2001GL014562, 2002.

Aponte, N., Gonzalez, S. A., Kelley, M. C., Tepley, C. A., Pi, X., and Iijima, B. A.: Advection of the equatorial anomaly over Arecibo by small-storm related disturbance dynamo electric fields, Geophys. Res. Lett., 27, 2833-2836, 2000.

Bailey, G. J., Sellek, R., and Rippeth, Y.: A modeling study of the equatorial topside ionosphere, Ann. Geophys., 11, 263, 1993.

Balan N. and Bailey, G. J.: Equatorial plasma fountain and its effects: Possibility of an additional layer, J. Geophys. Res., 100, 21 421-21 432, 1995.

Balan N., Bailey, G. J., Abdu, M. A., Oyama, K. I., Richards, P. G., MacDougall, J., and Batista, I. S.: Equatorial plasma fountain and its effects over three locations: Evidence for an additional layer, the F3 layer, J. Geophys. Res., 102, 2047-2056, 1997.

Balan N., Batista, I. S., Abdu, M. A., MacDougall, J., and Bailey, G. J.: Physical mechanism and statistics of occurrence of an additional layer in the equatorial ionosphere, J. Geophys. Res., 103, 29 169-29 181, 1998.

Blanc, M. and Richmond, A. D.: The ionospheric disturbance dynamo, J. Geophys. Res., 85, 1669-1686, 1980.

Banks, P. M., Foster, J. C., and Doupnik, J. R.: Chantanika radar observations relating to the latitudinal and local time variations of Joule heating, J. Geophys. Res., 86, 6869-6878, 1981.

Baumjohann, W., Kamide, Y., and Nakamura, R.: Substorms, storms, and the near-Earth tail, J. Geomag. Geoelec., 48, 177185, 1996.

Buonsanto M. J. and Titheridge J. E.: Diurnal variations in the flux of ionisation above the F2 peak in the northern and Southern Hemispheres, J. Atmos. and Solar-Terr. Phys., 49(11/12), 1093 1105, 1987.

Buonsanto, M. J.: Ionospheric storms-A review, Space Sci. Rev., 88, 563-601, 1999.

Buonsanto, M. J., Gonzalez, S. A, Pi, X., Ruohoniemi, J. M., Sulzer, M. P., Swartz, W. E., Thayer, J. P., and Yuan, D. N.: Radar chain study of the May, 1995 storm, J. Atmos. Sol. Terr. Phys., 61, 233-248, 1999.

Dudeney, J. R.: The accuracy of simple methods for determining the heighgt of the maximum electron concentration of the F2layer from scaled ionospheric characteristics, J. Atmos. Sol. Terr. Phys., 45, 629-640, 1983.

Dyson, P. L., Davies, T. P., Parkinson, M. L., Reeves, A. J., Richards, P. G., and Fairchild, C. E.: Thermospheric neutral winds at southern mid-latitudes: A comparison of optical 
and ionosonde hmF2 methods, J. Geophys. Res., 102, 27 18927 196, 1997.

Farley, D. T.: Early incoherent scatter observations at Jicamarca, J. Atmos. Terr. Phys., 53, 665-675, 1991.

Fejer, B. G., Gonzalez, C. A., Farley, D. T., and Kelly, M. C.: Equatorial electric fields during magnetically disturbed conditions, 1 , the effect of the interplanetary magnetic field, J. Geophys. Res., 84, 5797-5802, 1979.

Fejer, B. G., Larsen, M. F., and Farley, D. T.: Equatorial disturbance dynamo electric fields, Geophys. Res. Lett., 10, 537-540, 1983.

Fejer, B. G.: Equatorial ionospheric electric fields associated with magnetospheric disturbances, in Solar Wind Magnetosphere Coupling, edited by Kamide, Y., and Slavin, J. A., 519-545, Terra Sci., Tokyo, 1986.

Fejer, B. G. and Scherliess, L.: Time dependent response of equatorial ionospheric electric fields to magnetospheric disturbances, Geophys. Res. Lett., 22, 851-854, 1995.

Fejer, B. G. and Scherliess, L.: Empirical models of storm time equatorial electric fields, J. Geophys. Res., 102, 24 047-24 056, 1997.

Foster, J. C., Maurice, J.-P. St., and Abreu, V. J.: Joule heating at high latitudes, J. Geophys. Res., 88, 4885-4896, 1983.

Foster, J. C., Erickson, P. J., Coster, A. J., Goldstein, J., and Rich, F. J.: Ionospheric signatures of plasmaspheric tails, Geophys. Res. Lett., 29(13), 10.1029/2002GL015067, 2002.

Fuller-Rowell, T. J., Codrescu, M. V., Moffett, R. J., and Quegan, S.: Response of the thermosphere and ionosphere to geomagnetic storms, J. Geophys. Res., 99, 3893-3914, 1994.

Fuller-Rowell, T. J., Codrescu, M. V., Rishbeth, M. V., Moffett, R. J., and Quegan, S.: On the seasonal response of the thermosphere and ionosphere to geomagnetic storms, J. Geophys. Res., 101, 2343-2353, 1996.

Gamache, R. R., Reinisch, B. W., and Kersey, W. T.: ARTIST electron density profile algorithm, Sci. Rep., 468, Cent. for Atmos. Res., Univ. of Mass., Lowell, 1992.

Gonzales, C. A., Kelley, M. C., Fejer, B. G. Vickrey, J. F., and Woodman, R. F.: Equatorial electric fields during magnetically disturbed conditions, 2, Implications of simultaneous auroral and equatorial measurements, J. Geophys. Res., 84, 5803-5812, 1979.

Gupta, J. K. and Singh, L.: Long term ionospheric electron content variations over Delhi, Ann. Geophys., 18, 1635-1644, 2001,

SRef-ID: 1432-0576/ag/2000-18-1635.

Huang, Y.-N. and Cheng, K.: Ionospheric disturbances at the equatorial anomaly crest region during the March 1989 magnetic storms, J. Geophys. Res., 96, 13 952-13 965, 1991.

Jakowski, N.: TEC Monitoring by using satellite positioning system, in Modern Ionospheric science, (Eds.) Kohl, K., Rüster, R., and Schlegel, K., European Geophysical Society, KatlenburgLindau, 371-390, 1996.

Kelley, M. C., Fejer, B. G., and Gonzales, C. A.: An explanation for anomalous equatorial ionospheric electric fields associated with a northward turning of the interplanetary magnetic field, Geophys. Res. Lett., 6, 301-304, 1979.

Klobuchar, J. A., Basu, S., and Doherty, P.: Potential limitations in making absolute ionospheric measurements using dualfrequency radio waves from GPS satellites, in Proceedings of the Seventh International Ionospheric Effects Symposium, (Ed.) Goodman, J., 187, SRI International, Arlington, Va., 1993.

Lakshmi, D. R., Veenadhari, B., Dabas, R. S., and Reddy, B. M.: Sudden post-midnight decrease in equatorial F-region electron densities associated with severe magnetic storms, Ann. Geo- phys., 15, 306-313, 1997,

SRef-ID: 1432-0576/ag/1997-15-306.

Liu, J. Y., Tsai, H. F., Wu C.-C., Tseng, C. L., Tsai, L.-C., Tsai, W. H., Liou, K., and Chao, J. K.: The effect of geomagnetic storm on ionospheric total electron content at the equatorial anomaly region, Adv. Space Res., 24, 1491-1494, 1999.

Liu L., Wan, W., Lee, C. C., Ning, B., and Liu, J. Y.: The low latitude ionospheric effects of the April 2000 magnetic storm near the longitude $120^{\circ}$ E, Earth Planets Space., 56, 607-612, 2004.

Mannucci, A. J., Tsurutani, B. T., Guarnieri, F. L., Komjathy, A., Wilson, B. D., Iijima, B. A., Kozyra, J. U., and Gonzalez, W. D.: The Ionospheric Response to the Interplanetary Events of 29th and 30th October, 2003, Eos Trans. AGU, 84(46), Fall Meet. Suppl., Abstract SM51F-0620, 2003.

Mansilla G. A.: Disturbances at F2-region heights of equatorial anomaly during geomagnetic storms, J. Atmos. Sol. Terr. Phys., 65, 987-995, 2003.

Mazaudier, C. and Venkateswaran, S. V.: Delayed ionospheric effects of the geomagnetic storms of 22 March 1979 studied by the sixth co-ordinated data analysis workshop (CDAW-6), Ann. Geophys., 8, 511-518, 1990.

Preble, A. J., Anderson, D. N., Fejer, B. G., and Doherty, P. H.: Comparison between calculated and observed $\mathrm{F}$ region electron density profiles at Jicamarca, Peru, Radio Sci., 29, 857-866, 1994.

Prölss, G. W.: Ionospheric F-region storms, in Handbook of Atmospheric Electrodynamics, Vol. 2, (Ed.) Volland, H., 195-248, CRC Press, Boca Raton, F/a., 1995.

Prölss, G. W., Werner, S., Codrescu, M. V., Fuller-Rowell, T. J., Burns, A. G., and Killeen, T. L.: The thermospheric-ionospheric storm of 8 December 1982: Model predictions and observations, Adv. Space Res., 22, 123-128, 1998.

Reddy C. A. and Nishida, A.: Magnetorpheric substorms and nighttime height changes of the $\mathrm{F} 2$ region at middle and low latitudes, J. Geophys. Res., 97, 3039-3061, 1992.

Rishbeth, H.: How the thermospheric circulation affects the ionospheric F2-layer, J. Atmos. Sol. Terr. Phys., 60, 1385-1402, 1998.

Rostoker, G.: Phenomenology and physics of magnetospheric substorms, J. Geophys. Res., 97, 12 955-12 973, 1996.

Rüster, R. and King, J. W.: Negative ionospheric storms caused by thermospheric winds, J. Atmos. Sol. Terr. Phys., 38, 593-598, 1976.

Sastri, J. H.: Equatorial electric fields of ionospheric disturbance dynamo origin, Ann. Geophys., 6, 635-642, 1988.

Sastri, J. H., Ramesh, K. B., and Ranganath Rao, H. N.: Transient composite electric field disturbances near dip equator associated with auroral substorms, Geophys. Res. Lett., 19, 1451-1454, 1992.

Scherliess, L. and Fejer, B. G.: Storm time dependence of equatorial disturbance dynamo zonal electric fields, J. Geophys. Res., 102, 24 037-24 046, 1997.

Senior, C. and Blanc, M.: On the control of magnetospheric convection by the spatial distribution of ionospheric conductivities, J. Geophys. Res., 89, 261-284, 1984.

Skoug, R. M., Gosling, J. T., Steinberg, J. T., McComas, D. J., Smith, C. W., Ness, N. F., Hu, Q., and Burlaga, L. F.: Extremely high speed solar wind: 29-30 October 2003, J. Geophys. Res., 109, A09102, doi:10.1029/2004JA010494, 2004.

Sobral, J. H. A., Abdu, M. A., Gonzalez, W. D., Tsurutani, B. T., Batista, I. S., and Gonzalez, C. A.: Effects of intense storms and substorms on the equatorial Ionosphere/Thermosphere system 
in the American sector from ground-based and satellite data, J. Geophys. Res., 102, 14 305-14313, 1997.

Sobral, J. H. A., Abdu, M. A., Yamashita, C. S., Gonzalez, W. D., Gonzalez, C. A., Batista, I. S., Zamlutti, C.J., and Tsurutani, B.T.: 2001: Responses of the low-latitude ionosphere to very intense geomagnetic storms, J. Atmos. Sol. Terr. Phys., 63, 965974, 2001.

Somayajulu, V. V., Krishna Murthy B. V., and Subbarao, K. S. V.: Response of night-time equatorial F-region to magnetic disturbances, J. Atmos. Terr. Phys., 53, 965-976, 1991.

Spiro, R. W., Wolf, R. A., and Fejer, B. G.: Penetration of highlatitude electric-field effects to low latitudes during SUNDIAL 1984, Ann. Geophys., 6, 39-50, 1988.

Tsunomura, S. and Araki, T.: Numerical analysis of equatorial enhancement of geomagnetic sudden commencement, Planet. Space Sci., 32, 599-604, 1984.
Vasyliunas, V. M.: The interrelationship of magnetospheric processes, in Earth's Magnetosphere Processes, edited by M. McCormac, D. Reidel, Norwell, Mass., 29-38, 1972.

Vlasov, M., Kelley, M. C., and Kil, H.: Analysis of ground-based and satellite observations of F-region behavior during the great magnetic storm of 15 July, J. Atmos. Sol. Terr. Phys., 65, 12231234, 2003.

Walker, G. O. and Wong, Y. W.: Ionospheric effects observed throughout East Asia of the large magnetic storm of 13-15 March 1989, J. Atmos. Terr. Phys., 55, 995-1008, 1993.

Wolf, R. A., Harel, M., Spiro, R. W., Voigt, G.-H., Reiff, P. H., and Chen, C.-K.: Computer simulation of inner magnetospheric dynamics for the magnetic storm of 29 July 1977, J. Geophys. Res., 87, 5949-5962, 1982.

Yeh, K. C., Ma, S. Y., and Lin, K. H.: Global ionospheric effects of the October 1989 geomagnetic storm, J. Geophys. Res., 99, 6201-6218, 1994. 